\title{
Removal of a knotted stimulating femoral nerve catheter using a saline bolus injection
}

\author{
This article was published in the following Dove Press journal: \\ Local and Regional Anesthesia \\ I July 2010 \\ Number of times this article has been viewed
}

\author{
Mark C Kendall \\ Antoun Nader \\ Robert B Maniker \\ Robert J McCarthy \\ Department of Anesthesiology, \\ Northwestern University Feinberg \\ School of Medicine, Chicago, IL, USA
}

Correspondence: Mark C Kendall

Department of Anesthesiology, 25 I

E. Huron, F5-704, Chicago, IL 606 I I, USA

$\mathrm{Tel}+\mathrm{I} 3129268369$

Fax + I 312926834|

Email m-kendall@northwestern.edu
Objective: Stimulating peripheral nerve catheters have become increasingly popular as part of postoperative multimodal analgesia for total knee arthroplasty. We describe a case of a successful nonsurgical removal of a knotted stimulating femoral nerve catheter after saline expansion of the catheter pocket at the bedside.

Case report: A 65-year-old female underwent total knee arthroplasty under combined spinal epidural anesthesia. Postoperatively, a stimulating femoral nerve catheter was placed without complication. The catheter was threaded $12 \mathrm{~cm}$ past the needle tip with minimal resistance. Function of the catheter was verified by loss of pinprick sensation in the femoral nerve distribution and excellent analgesic efficacy was achieved. The first attempt at catheter removal was unsuccessful. Thigh flexion and rotation also failed to facilitate catheter removal. The catheter was then left to continuous tension for 6 hours, but further attempts at removal remained unsuccessful. Under ultrasound visualization, $10 \mathrm{~mL}$ of saline was injected through the catheter with moderate resistance and without patient discomfort, after which the catheter was removed using minimal tension. The catheter was intact but had a single knot at the distal end of the catheter.

Conclusions: We present a rare case of a knotted stimulating catheter in which the use of a saline bolus to dilate the catheter pocket proved to be successful after other simple methods of catheter removal had failed. Given the simple nature of this technique, it can be attempted at the bedside before more invasive procedures are planned.

Keywords: femoral nerve catheter, catheter removal

\section{Introduction}

Catheters used for continuous femoral nerve block blockade may contain electrodes and wires for assessment of elicited motor response. Catheter related events such as kinking, displacement, blockage, and knotting are frequently reported following placement of nonstimulating catheters, ${ }^{1-3}$ however, to our knowledge, there are no published case reports of a knotted stimulating peripheral nerve catheter.

Knotted catheters may be difficult to remove despite repositioning of the patient or guide wire placement in an effort to release entrapment. ${ }^{4,5}$ Injection of $0.9 \%$ saline solution to facilitate catheter placement is frequently performed, however, no report has described the use of a saline injection to facilitate the removal of a knotted catheter. ${ }^{6}$ We report a case of successful removal of a knotted stimulating femoral nerve catheter after saline expansion of the catheter pocket at the bedside.

\section{Case report}

A 65-year-old female underwent total knee arthroplasty under combined spinal epidural anesthesia. Intraoperative sedation consisted of a propofol infusion and 
intermittent midazolam administration. Postoperatively, following complete resolution of the spinal analgesia, the groin area was cleaned and draped for the procedure. A $25 \mathrm{~mm}$ broadband linear array transducer (7-13 $\mathrm{MHz}$ probe, Sonosite, M Turbo, Bothell, WA, USA) was placed within a plastic sterile sheath and positioned below the inguinal ligament in a transverse plane to the femoral artery and nerve. The skin at the needle entry site was infiltrated with 2 $\mathrm{mL}$ of lidocaine $1 \%$ using a 25 -gauge, $1 \frac{1}{2}{ }^{\text {" hypodermic nee- }}$ dle. A $7 \mathrm{~cm}$ 18-gauge stimulating Tuohy needle (StimuCath ${ }^{\circledR}$; Arrow International, Reading, PA, USA) connected to the negative lead of a constant current output peripheral nerve stimulator (Stimuplex DIG ${ }^{\circledR}$; B-Braun/McGaw Medical, Bethlehem, PA, USA) was inserted out-of-plane at the inguinal crease. The stimulation frequency was set at $2 \mathrm{~Hz}$, a pulse width of $100 \mu$ s and a stimulating current of $1 \mathrm{~mA}$. When a quadriceps contraction was elicited, a 20-gauge stimulating catheter (StimuCath ${ }^{\circledR}$; Arrow International) connected to the nerve stimulator was inserted through the needle and advanced while maintaining an evoked motor response until resistance was met.

The stimulating catheter was threaded $12 \mathrm{~cm}$ past the needle tip. The catheter was secured by subcutaneous tunneling $5 \mathrm{~cm}$ lateral to the insertion site. A test dose ( $5 \mathrm{~mL}$ ) of lidocaine $75 \mathrm{mg}$ with epinephrine $15 \mathrm{~g}$ was then administered. A $50 \mathrm{mg}$ bolus dose of ropivacaine $0.25 \%$ was administered slowly through the catheter and the patient was monitored for intravascular injection. The catheter was then attached to a portable infusion pump set to deliver $5 \mathrm{~mL}$ of $0.1 \%$ ropivacaine per hour. The function of the catheter was verified by loss of pinprick sensation in the femoral nerve distribution including the saphenous (medial leg) nerve, and excellent analgesic efficacy was achieved.

On the morning of postoperative day 2 , the ropivacaine infusion was discontinued. Four hours later, following complete sensory resolution of the block, resistance was met at approximately the $5 \mathrm{~cm}$ marking, and the catheter could not be withdrawn further. The patient was asked to shift position to decrease tension on the catheter, without success. Additional patient maneuvers included thigh flexion and rotation, and supine positioning of the patient, which all failed to facilitate removal. The catheter was pulled taut and secured with adhesive tape to the patient's thigh for 6 hours, but attempts at removal remained unsuccessful. Ultrasound examination of the groin failed to visualize the reason for entrapment. Ten milliliters of $0.9 \%$ saline were then injected through the femoral nerve catheter with moderate resistance, but without patient discomfort. The saline expansion was visualized beneath the fascia iliaca. The catheter was then removed using minimal force. The catheter was intact but had a single knot at the distal end of the catheter (Figure 1).

\section{Discussion}

Peripheral nerve catheters are frequently used as part of multimodal analgesic management for patients undergoing knee surgery, thus increasing the likelihood of encountering catheter related complications as we report. Although knots or kinks in epidural catheters have been more frequently reported, ${ }^{7,8}$ the incidence of this catheter related event following femoral nerve catheterization is estimated to be on the order of $0.13 \%$ of placements. ${ }^{5}$

Patient manipulations are the most frequently attempted initial methods to free entrapped catheters. These methods may be unsuccessful as in our case, and other maneuvers are used to remove the catheters. Burgher et al described seven cases in which knotted peripheral nonstimulating catheters were successfully removed by a fluoroscopy-guided wire after unsuccessful attempts by standard methods. ${ }^{5}$ Surgical intervention following unsuccessful bedside maneuvers have also been reported with the use of nonstimulating catheters (Table 1).
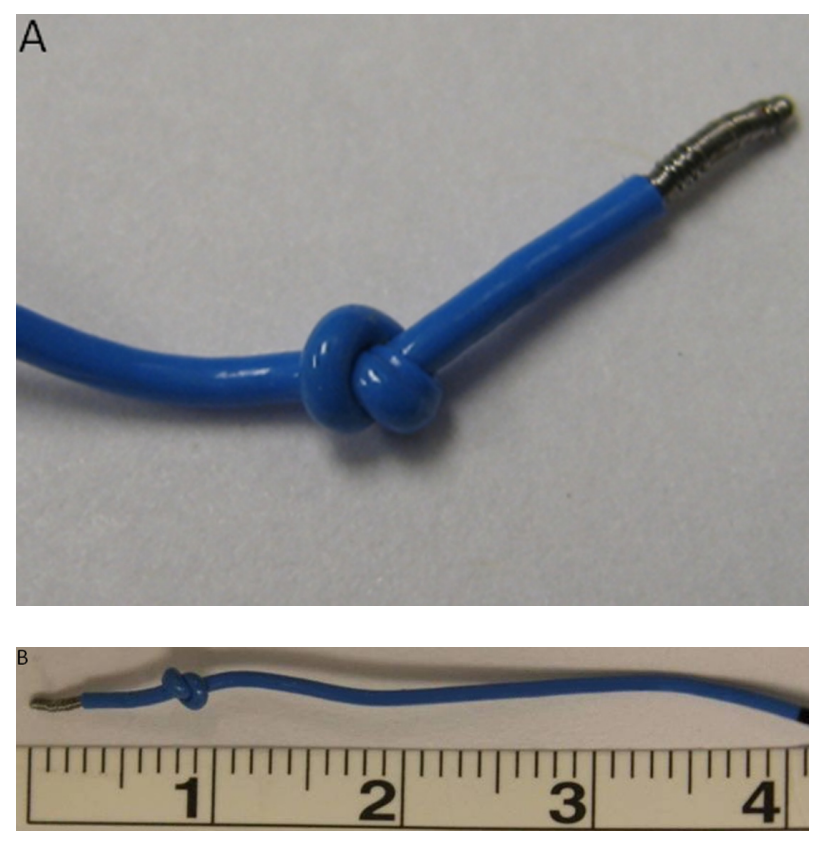

Figure I Knotted stimulating femoral nerve catheter following its removal using saline expansion beneath the fascia iliaca. (A) A close-up of the stimulating knotted catheter. (B) The knot is located less than I cm from the tip of the catheter. Notice how the catheter is shorter than its original length; the black mark resembles $5 \mathrm{~cm}$ in an unknotted catheter. 
Table I Reports of knotted peripheral nerve catheters

\begin{tabular}{|c|c|c|c|c|}
\hline Investigator & $\begin{array}{l}\text { Number } \\
\text { of cases }\end{array}$ & Catheter distance & $\begin{array}{l}\text { Type of } \\
\text { catheter }\end{array}$ & Successful removal methods \\
\hline Present study & 1 & $12 \mathrm{~cm}$ (beyond needle tip) & Stimulating & Saline injection through catheter \\
\hline Burgher et $\mathrm{al}^{5}$ & 8 & $10 \mathrm{~cm}$ (beyond needle tip) & Nonstimulating & $\begin{array}{l}7 \text { - fluoroscopy guided technique } \\
\text { I - patient repositioning }\end{array}$ \\
\hline Offerdahl et $\mathrm{al}^{4}$ & I & $10 \mathrm{~cm}$ (beyond needle tip) & Nonstimulating & I - patient repositioning \\
\hline MacLeod et al ${ }^{1, *}$ & I & $5 \mathrm{~cm}$ (within sheath) & Nonstimulating & Surgical incision \\
\hline Rudd et $\mathrm{al}^{2}$ & I & $20 \mathrm{~cm}$ (at skin) & Nonstimulating & Surgical incision \\
\hline Motamed et $\mathrm{al}^{3}$ & I & 14 cm (at skin) & Nonstimulating & Surgical incision \\
\hline
\end{tabular}

Note: *Sciatic nerve catheter.

We present a case of a single knotted catheter, in which the use of a saline bolus to dilate the catheter pocket proved to be successful after other simple bedside methods of catheter removal had failed. We observed the saline spread under the fascia iliaca lateral to the nerve. The injection of $10 \mathrm{~mL}$ was without patient discomfort. Although injecting saline or $5 \%$ dextrose has been suggested as a method to facilitate catheter placement, ${ }^{3,9}$ our case suggests that injection of saline may facilitate catheter removal by expanding the surrounding passage.

The optimal length of femoral catheter insertion is unknown. Advancement of the catheter $16-20 \mathrm{~cm}$ beyond the needle tip may be desirable to achieve blockade of the lumbar plexus. ${ }^{10}$ However, catheter threading beyond $10 \mathrm{~cm}$ may be a risk factor for knotting in a peripheral catheter. In our experience, (approximately 80 catheters per month), to avoid leakage and dislodgement we advance the catheter until resistance is encountered. This practice may increase the propensity of kinking and knotting. In our case, the catheter was threaded $12 \mathrm{~cm}$ beyond the needle tip, which is concordant with other reported cases of knotted femoral nerve catheters (Table 1).

The 20-gauge stimulating catheter was placed using an 18 -gauge touhy needle. The catheter was withdrawn out of the skin through the 18-gauge insertion point with saline escaping from the insertion point with minimal resistance and no patient discomfort. We speculate that using an 18-gauge touhy needle, the entry point is larger in diameter relative to the diameter of the stimulating catheter, and together with the expansion of the perineural space widening the path the catheter had taken, no incision was needed to be performed to remove the knotted catheter.

The use of ultrasonography allowed us to visualize the spread of saline injected through the catheter and assisted in identifying the location of the catheter tip and its proximity to the vital anatomical structures (ie, femoral nerve, femoral artery) which may influence the decision to continue to apply tension versus surgical exploration. This may also help identifying the knot by creating an echogenic contrast with the surrounding fluid. The expansion of the space and the catheter location was visualized lateral to the femoral nerve. The expansion of the perineural space with saline widens the space, providing a wider passage allowing the knot to be removed through the 18-gauge insertion point.

Despite the theoretical increased rigidity of stimulating peripheral nerve catheters due to the enclosed wire, the risk of knotting may be similar to nonstimulating catheters. The presence of a low volume fluid bolus is a low risk intervention unlikely to harm the patient and is easily performed at the bedside. Given the simple nature of this technique, dilation of the catheter pocket should be attempted at the bedside before more invasive procedures are planned.

\section{Acknowledgments}

Presented in part at the 2009 Annual Spring Meeting of the American Society of Regional Anesthesia and Pain Medicine, Phoenix AZ, USA.

\section{Disclosure}

The authors report no conflicts of interest in this work.

\section{Financial support}

\author{
Departmental
}

\section{References}

1. MacLeod D. Knotted peripheral nerve catheter: letter to the editor. Reg Anesth Pain Med. 2003;28(5):487-488.

2. Rudd K, Hall J. Knotted femoral nerve catheter. Anaesth Intensive Care. 2004;32(2):282-283.

3. Motamed C, Bouaziz H, Mercier FJ, Benhamou D. Knotting of a femoral catheter: letter to the editor. Reg Anesth. 1997;22(5):486-487.

4. Offerdahl MR, Lennon R, Horlocker T. Successful removal of a knotted fascia iliaca catheter: principals of patient positioning for peripheral nerve catheter extraction. Anesth Analg. 2004;99:1550-1552.

5. Burgher A, Hebl J. Minimally invasive retrieval of knotted nonstimulating peripheral nerve catheters. Reg Anesth Pain Med. 2007;32:162-166. 
6. Pham Dang C, Guilley J, Dernis L, et al. Is there any need for expanding the perineural space before catheter placement in continuous femoral nerve blocks? Reg Anesth Pain Med. 2006;31:393-400.

7. Browne RA, Politi VL. Knotting of an epidural catheter: a case report. Cana Anaesth Soc J. 1979;29:142-144.

8. Gozal D, Gozal Y, Beilin B. Removal of knotted epidural catheters. Reg Anesth. 1996;21:71-73.
9. Tsui B, Kropelin B, Ganapathy S, Finucane B. Dextrose 5\% in water: fluid medium for maintaining electrical stimulation of peripheral nerves during stimulating catheter placement. Acta Anaesthesiologica Scand. 2005;49:1562-1565.

10. Capdevila X, Biboulet P, Morau D, et al. Continuous three-in-one block for postoperative pain after lower limb orthopedic surgery: where do the catheters go? Anesth Analg. 2002;94:1001-1006.

\section{Publish your work in this journal}

Local and Regional Anesthesia is an international, peer-reviewed, open access journal publishing on the development, pharmacology, delivery and targeting and clinical use of local and regional anesthetics and analgesics. The journal welcomes submitted papers covering original research, basic science, clinical studies, reviews \& evaluations, guidelines, expert opinion and commentary, case reports and extended reports. The manuscript management system is completely online and includes a very quick and fair peer-review system, which is all easy to use. Visit http://www.dovepress.com/testimonials.php to read real quotes from published authors. 